Griggs, M. S., Gagnon, S. G., Huelsman, T. J., Kidder-Ashley, P., \& Ballard, M. (2009). Student-teacher relationships matter: Moderating influences between temperament and preschool social competence. Psychology in the Schools, 46(6): 553-567 (Jul 2009). Published by Wiley (ISSN: 0033-3085). DOI: 10.1002/pits.20397 [The definitive version is available at www3.interscience.wiley.com]

\title{
Student-Teacher Relationships Matter: Moderating Influences Between Temperament and Preschool Social Competence
}

Marissa Swaim Griggs, Sandra Glover Gagnon, Timothy J. Huelsman, Pamela Kidder-Ashley, and Mary Ballard

\begin{abstract}
Ecological approaches to preschool assessment, which consider both within-child and environmental variables, are considered best practice for school psychologists. This study employs such a model to investigate the interactive influence of child temperament and student-teacher relationship quality on peer play behaviors. Parents of 44 preschool children ( 25 girls, 19 boys) ranging in age from 40 to 68 months (mean $[M]=53.00)$ and primarily White $(92.9 \%)$ provided ratings of their children's temperaments on the Behavioral Style Questionnaire. Their teachers completed the Student-Teacher Relationship Scale and the Penn Interactive Peer Play Scale. Results indicate that (a) student-teacher relationships characterized by low conflict and low dependence are associated with less disruptive peer play, and (b) the association between temperament and disruptive play is attenuated in low conflict student-teacher relationships. Implications for school psychologists include the importance of student-teacher relationships in the context of preschool assessment and intervention planning.
\end{abstract}


Experts in early childhood assessment long have advocated for a multifaceted, ecological approach to the assessment of preschoolers' developmental skills that examines school and home contexts (Neisworth \& Bagnato, 2005). For school psychologists, best practice involves evaluating children's environments to identify potential targets for intervention and directly link assessment results to intervention. In practice, it is typical to evaluate within-child traits (e.g., intelligence, social competence); it is less common to assess aspects of the child's social environment (e.g., student-teacher relationships). This practice occurs despite a large body of empirical support for the importance of social environmental variables in the development of young children's social competence (Coolahan, Fantuzzo, Mendez, \& McDermott, 2000; Davis, 2003; Fantuzzo, Sekino, \& Cohen, 2004; Hamre \& Pianta, 2001, 2006; Pianta \& Stuhlman, 2004).

In addition to examining children's social environments individually, early childhood researchers and theorists have advocated for more research to evaluate how those variables interact with within-child characteristics to influence various developmental outcomes (DiLalla, Marcus, \& Wright-Phillips, 2004). Temperament, or an individual's innate style of responding behaviorally and emotionally to the environment, is associated with a variety of school-related outcomes (Blair, Denham, Kochanoff, \& Whipple, 2004; Bohlin, Hagekull, \& Andersson, 2005; Coplan, Barber, \& Lagac'e-S'eguin, 1999; DiLalla et al., 2004; Martin, 1989) and is an important within-child variable to assess in young children. The present study relies on the conceptualization of temperament purported by Thomas, Chess, and Birch (1968), who proposed 9 domains of temperament: Activity, Rhythmicity, Approach, Adaptability, Intensity, Mood, Persistence, Distractibility, and Threshold.

The goodness-of-fit model, also conceptualized by Thomas and Chess (1977), provides an appropriate framework from which to conceptualize an ecological approach to assessment and forms the foundation for the present study, which investigated the interaction between child temperament (a within-child variable) and student-teacher relationship quality (an ecological variable) in the prediction of social competence, as evidenced by the quality of peer play interactions. From this perspective, the quality of the fit between temperament and the surrounding environment plays amore important role in determining various child outcomes than either temperament or the environment alone. The following review of existing literature reveals important links between each of these variables and a variety of child developmental outcomes.

\section{Student-Teacher Relationships}

Relationships with significant adults are fundamental for children's intellectual, social, and emotional development (Pianta, 1999). Research strongly supports the importance of student-teacher relationships in predicting school-related outcomes (Davis, 2003; Hamre \& Pianta, 2001; Howes, Matheson, \& Hamilton, 1994; Hughes, Cavell, \& Willson, 2001; Pianta \& Stuhlman, 2004) and consistently indicates that positive student-teacher relationships are associated with desirable outcomes. Close relationships with teachers predict healthy socioemotional development (Pianta, 1999) as well as adjustment to (Birch \& Ladd, 1997; Ladd, Birch, \& Buhs, 1999) and success in school (Hamre \& Pianta, 2006). Negative relationships are linked consistently to a variety of adverse outcomes: behavioral problems (Pianta, Steinberg, \& Rollins, 1995), dislike for and avoidance of school (Birch \& Ladd), adjustment problems (Pianta, Nimetz, \& Bennett, 1997), and less developed concept knowledge (Pianta et al., 1995). Dependent relationships between children and teachers also have been linked to poor academic performance, negative attitudes toward school, less positive engagement with the school environment (Birch \& Ladd), and undesirable classroom behaviors (Pianta \& Nimetz, 1991). Last, children experiencing conflictual and dependent relationships with teachers tend to exhibit poorer academic performance than those in less conflictual and dependent relationships (DiLalla et al., 2004). 
Not only has previous research yielded substantial evidence for direct links between studentteacher relationships and various outcomes, it also has suggested a moderating role for such relationships (Burchinal, Peisner-Feinberg, Pianta, \& Howes, 2002; Hamre \& Pianta, 2001; Hughes, Cavell, \& Jackson, 1999; Ladd \& Burgess, 2001). For example, close relationships have been found to serve as protective factors for children at risk for academic problems due to family characteristics (Burchinal et al.). For children with histories of aggressive behavior, close relationships with teachers have predicted decreased aggressive behavior in subsequent school years (Hughes et al.). Conversely, longitudinal research has indicated that conflictual student-teacher relationships are linked with conduct problems and disturbed thinking patterns for children at risk for maladjustment due to existing patterns of aggressive behavior (Ladd \& Burgess). Relationships marked by conflict and dependency also have predicted academic and behavioral problems through eighth grade, particularly for children identified as having higher numbers of behavioral problems than their peers in kindergarten (Hamre \& Pianta).

The research reviewed provides evidence for the importance of the student-teacher relationship for children at risk for academic and behavioral problems. Child temperament is a within-child trait that may place children at risk for undesirable outcomes (Coplan et al., 1999; LaForce \& Oxford, 2008). Given the potential for children with difficult temperaments to experience schoolrelated difficulties, a positive student-teacher relationship may mitigate the association between temperament and social outcomes.

\section{Child Temperament}

Although temperament has been examined in numerous empirical studies of child development (Blair et al., 2004; Bohlin et al., 2005; DiLalla et al., 2004), school psychologists and educators evaluate it infrequently, and it is rarely considered in formal, school-based, early childhood assessment batteries (Carey, 1998). To address this deficit, experts advocate for the inclusion of standardized measures of temperament in comprehensive psychoeducational evaluations and in educational decision making and intervention planning (Carey, 1998; Keogh, 2003).

The rationale for assessing temperament is based on its association with a variety of schoolrelated competencies, including school adjustment, classroom behaviors, and social withdrawal (Coplan et al., 1999; LaForce \& Oxford, 2008; Martin, 1989). For example, children who exhibit longer attention spans, lower activity levels, and less negative emotionality tend to demonstrate stronger school readiness skills during preschool (Coplan et al.). Similarly, elevated distractibility, high activity level, and low persistence predict poorer academic achievement; lower levels of constructive, self-directed behavior; and higher amounts of inappropriate gross-motor behavior (Martin, 1989). Additionally, shyness and poor inhibitory control in preschool are associated with social withdrawal in subsequent grades (LaForce \& Oxford).

These findings provide substantial evidence for the link between child temperament and a number of important school-related skills/abilities. Social competence is one critical aspect of school readiness and adjustment (Denham, 2006; Ladd, Herald, \& Kochel, 2006; Raver \& Knitzer, 2002), and will be examined in relation to temperament. 


\section{Social Competence}

The development of social competence is a critical task during early childhood (Sroufe, Egeland, Carlson, \& Collins, 2005). Socially competent children are effective in social interactions (RoseKrasnor, 1997; Sroufe et al.) and display effective problem-solving, emotional regulation, and communication skills (Sroufe et al.). Such children demonstrate sensitivity and empathy toward peers, engage in complex play, form friendships with peers, and exhibit the ability to solve social problems (Howes, Matheson, et al., 1994). Social competence is particularly critical in the context of overall school adjustment (Denham, 2006; La Paro \& Pianta, 2000; Ladd et al., 2006; Raver \& Knitzer, 2002).

One element of social competence in the school setting is peer play. The establishment of successful peer relationships is a fundamental developmental milestone for preschoolers (Sroufe et al., 2005) as friendships support their adjustment to the formal school context (Ladd, Kochenderfer, \& Coleman, 1996). Play is the primary activity through which preschoolers interact socially with peers, and it has strong implications for the development of social competence and future interpersonal relationships (Johnson, Ironsmith, Snow, \& Poteat, 2000; Ladd \& Price, 1987). Successful peer play interactions are associated with increased academic engagement and motivation as well as greater behavioral, social, and academic development (Coolahan et al., 2000; Fantuzzo, Bulotsky-Shearer, Fusco, \& McWayne, 2005; Fantuzzo et al., 2004). Conflictual interactions, by contrast, are related to more negative behavioral and emotional outcomes, including difficulties with school adjustment (Ladd et al.).

Positive early peer interactions are critical for the development of social competence, and they predict school adjustment. Thus, peer play quality will be investigated in relation to temperament and student-teacher relationships.

\section{Student-Teacher Relationships, Temperament, and Peer Play}

The literature provides ample evidence for an association between temperament and the quality of peer play interactions. For example, children who are less adaptable and more negative in mood tend to be neglected more often by their peers (Walker, Berthelsen, \& Irving, 2001). Higher levels of activity and distractibility, lower persistence and adaptability, and generally negative mood are associated with peer rejection (Walker et al.), and high activity level, intensity, and distractibility are negatively associated with prosocial behaviors during peer play (DiLalla, 1998). Children high in activity and low in adaptability tend to experience fewer successful peer play interactions in comparison to their more adaptable, more approaching, and less active peers (Mendez, Fantuzzo, $\&$ Cicchetti, 2002). More recent research has found links between inhibition, impulsivity, social competence, and peer play (Corapci, 2008).

Research also suggests that student-teacher relationship quality plays a role in the development of children's social competence (Howes, 2000; Howes \& Hamilton, 1993; Howes, Matheson et al., 1994; Pianta\&Stuhlman, 2004). Preschool children in secure relationships with their teachers engage in more complex play, display higher ego-resiliency and gregariousness, receive higher sociometric ratings (Howes, Matheson, et al., 1994), and exhibit lower levels of aggression in elementary school (Hughes et al., 1999) than do children in insecure relationships with their teachers. In contrast, conflictual early student-teacher relationships predict poor social competence (Pianta \& Stuhlman) and low levels of prosocial behavior (Birch \& Ladd, 1998). Dependent relationships in preschool are associated with aggression and withdrawal from the peer group (Howes, Hamilton, et al., 1994). In light of these findings, it is not difficult to imagine that children in conflictual and dependent 
relationships with teachers might have poorer play outcomes than their peers who enjoy better relationships with their teachers.

The literature presented provides a rationale for associations among student-teacher relationships, temperament, and peer play. As described in the following section, research consistently demonstrates differences between boys and girls in terms of temperament and student-teacher relationships. Thus, it is important to consider gender when examining these constructs.

\section{Gender, Student-Teacher Relationships, Temperament, and Social Competence}

Previous studies have revealed numerous gender differences in temperament traits. Preschool boys tend to be more active and distractible (Mendez, McDermott, \& Fantuzzo, 2002; Walker et al., 2001) and less persistent (Walker et al.), whereas girls exhibit more effortful control (Else-Quest, Hyde, Goldsmith, \& Van Hulle, 2006), task orientation, and traits related to social competency, such as personal/social adaptability, flexibility, and reactivity (Keogh, 2003). In the classroom, teachers more often report closer, less conflictual relationships with girls than boys (Birch \& Ladd, 1998; Hamre \& Pianta, 2001; Hughes et al., 2001; Murray \& Murray, 2004). Additionally, girls tend to display more socially competent behaviors than do boys (Birch \& Ladd; Coolahan et al., 2000). Thus, any empirical study of the relationships among temperament, student-teacher relationships, and school-related behavior must attend to the issue of gender.

\section{Conceptual Framework}

To bring these ideas together, we use the goodness-of-fit framework, also conceptualized as the "child $\times$ environment" model, in which temperament is considered in relation to pertinent ecological variables. Researchers have asserted the usefulness of examining goodness of fit with regard to child temperament and student-teacher interactions (Keogh, 1989; Thomas \& Chess, 1977), particularly when predicting children's school-related outcomes (e.g., Keogh, 1994; Ladd et al., 1999). Temperament affects children's interpretations of and reactions to environmental stimuli, which may influence how others respond to them. Keogh's $(1989,1994)$ research on the relationship between child temperament and perceived "teachability" supports the goodness-of-fit model. In that research, teachability refers to teachers' judgments about their students with regard to how closely they resemble "model" students. Teachable students tend to be insightful, bright, and friendly, and they generally follow directions. Children who display difficult temperament patterns (e.g., low persistence, high distractibility, high activity, low adaptability, and high reactivity) are likely to be perceived as less teachable by their teachers.

\section{The Current Study}

Despite researchers' agreement that a child $\times$ environment (e.g., goodness-of-fit) approach is useful for understanding school adjustment (DiLalla et al., 2004; Ladd et al., 1999), the interaction between child temperament and student-teacher relationships rarely has been examined. Instead, the literature reveals ways in which temperament and student-teacher relationship quality are independently and directly linked to social competence. In this study we investigated the possibility that student-teacher relationship quality moderates the relationship between temperament and peer play. This idea is consistent with a goodness-of-fit model, as it considers not only the direct, independent 
effects of these variables on this particular outcome (Rothbart \& Bates, 2006) but also their interactive effects. This research is important because the identification of a moderating effect of the student-teacher relationship may offer a target for intervention.

We expected to find that both difficult temperaments and less desirable student-teacher relationships would predict disruptive peer play. We also expected that the interaction of these variables would contribute to the prediction of the criterion. These relationships may be different for girls and boys, but because the extant literature does not specify how gender might function in this moderated model, we opted for a control strategy rather than examining gender directly. Thus, we hypothesized that, after controlling for child gender, the positive relationship between temperament and peer play (e.g., difficult temperaments would be associated with more disruptive play) would be moderated by student-teacher relationship quality, such that better relationships would attenuate the strength of the temperament-peer play associations.

\section{METHOD}

\section{Participants}

This research was conducted as part of a larger study of 117 preschool children attending 1 of 19 participating daycare or preschool centers in Tennessee or North Carolina. Although data were collected from 88 parents and 74 teachers, only 44 children ( 25 girls, 19 boys) were included in the current study because the analyses required matched parent and teacher data. The children ranged in age from 40 to 68 months (mean $[M]=53.07$, standard deviation $[S D]=7.31$ ) and primarily were White $(n=41 ; 92.9 \%)$. The majority of teachers were White $(n=37 ; 84.1 \%)$ and had an average of 9.45 years of teaching/childcare experience $(S D=6.73 ; n=32$ reporting). Table 1 displays other teacher and parent characteristics.

\section{Measures}

Behavioral Style Questionnaire. The Behavioral Style Questionnaire (BSQ; McDevitt \& Carey, 1978) is a 110-item caregiver rating scale of child temperament designed for use with children from 3 to 7 years of age. One or both of the child's parents provided ratings (see Table 1) using a 6-point Likert-type scale, with responses ranging from "Almost Never" (1) to "Almost Always" (6). The BSQ comprises nine subscales that conform to the conceptualization of temperament identified by Thomas and Chess (1977) in the classic New York Longitudinal Study.

The BSQ was standardized on a sample $(N=350)$ of children who were predominately European-American, of middle socioeconomic status, and living in the eastern United States. Reliability of the scale was supported through a 1-month test-retest interval involving 53 children from the normative sample ( $\alpha=.67-.94$ for each dimension, median $=.81$, with total score $\alpha=.89$ ) and through split-half estimates $(\alpha=.47-.80$, median $=.70$, with $\alpha=.84$ for total instrument; McDevitt $\&$ Carey, 1978). Evidence for the validity of the scales is provided in the Carey Temperament Scales manual (Carey \& McDevitt, 2000) and by studies demonstrating links between the BSQ subscales and other measures of temperament (Novosad \& Thoman, 1999; Sarafino, 2000).

The current study examines an Easy/Difficult temperament dimension similar to the conceptualization by Thomas and Chess $(1977,1982)$. The Easy/Difficult dimension is a combination of five BSQ domains: Approach/Withdrawal (i.e., how the child reacts to new people, situations, places, foods, toys, etc.); Rhythmicity (i.e., the regularity of the child's physiological functions, including 
eating, sleeping, and toileting); Adaptability (i.e., how easily children's reactions can be modified in a particular direction); Intensity (i.e., the basic energy level of the child's responses); and Mood (i.e., how pleasant and friendly or unpleasant and unfriendly the child's behavior is in different situations). BSQ scores for each of these five temperament domains were calculated and added together to form one continuous Easy/Difficult dimension score, with higher scores reflecting more difficult behavioral styles and lower scores representing easier styles.

Table 1

Sample Characteristics: Teachers and Parents

\begin{tabular}{lrc}
\hline Teacher education level & Frequency & Percent \\
High school graduate & 1 & 2.3 \\
Some college/trade school & 14 & 31.8 \\
Associate's degree & 6 & 13.6 \\
Bachelor's degree & 13 & 29.5 \\
Some graduate/professional school & 1 & 2.3 \\
Graduate/Professional school degree & 3 & 6.8 \\
Parent education level & & \\
Some college/trade school & 4 & 9.1 \\
Associate's degree & 1 & 2.3 \\
Bachelor's degree & 14 & 31.8 \\
Some graduate/professional school & 2 & 4.5 \\
Graduate/Professional school degree & 18 & 40.9 \\
Parent forms completed by & & \\
Mother only & 18 & 40.9 \\
Father only & 2 & 4.5 \\
Both parents & 20 & 45.5 \\
\hline
\end{tabular}

Student-Teacher Relationship Scale. The Student-Teacher Relationship Scale (STRS; Pianta, 2001) assesses the quality of the relationships between teachers and their students. Intended for use with students in preschool through Grade 3 (ages 4 through 8 years), the STRS comprises three subscales (Conflict, Closeness, and Dependency) that reflect the aspects of the student-teacher relationship identified by Pianta (1999). To use the STRS, teachers rate 28 items on a 5-point Likert-type scale ranging from "Definitely Does Not Apply" (1) to "Definitely Applies" (5). The STRS was standardized with 275 teachers (all female, predominately White) and 1535 preschool through third-grade students (mean age $=5$ years). The student sample was predominately White $(63 \%)$ and consisted of $53 \%$ boys and $47 \%$ girls. Family socioeconomic status and maternal education levels varied widely.

The STRS has demonstrated strong reliability and validity (Pianta, 2001). Assessment of testretest reliability after a 4-week interval with a subset of the normative sample (24 teachers, 72 students) revealed statistically significant correlations for all scales $(r=.88$ for Closeness, $r=.92$ for Conflict, $r=.76$ for Dependency, and $r=.89$ for Total). Utilizing the entire normative sample, internal consistency reliability estimates for the Conflict and Closeness subscales and Total score were high $(\alpha=.92, .86$, and .89 , respectively) and for the Dependency subscale, moderately high $(\alpha=.64)$. Item-total correlations supported the inclusion of all 28 items. Results of validity studies indicate both predictive and concurrent validity in relation to behavioral and academic outcomes for students (Pianta, 2001). Construct validity was supported through the use of exploratory factor analysis and principal components analysis (Pianta, 2001). 
Penn Interactive Peer Play Scale. The Penn Interactive Peer Play Scale (PIPPS; Fantuzzo, Coolahan, Mendez, McDermott,\&Sutton-Smith, 1998) measures teachers' perceptions of children's play behaviors with peers. The PIPPS comprises three subscales: Play Interaction, Play Disruption, and Play Disconnection. The Play Disruption subscale, including behaviors such as arguing, name calling, and taking others' items, was used in the current study because children who exhibit these types of behaviors during play are at risk for negative outcomes (Ladd et al., 1996). To use the PIPPS, teachers rate 36 items rated on a 4-point Likert-type scale with responses ranging from "Never" (1) to "Always" (4).

The teacher PIPPS standardization sample included 523 Black preschool children from urban Head Start programs (Fantuzzo et al., 1998). Construct validity was confirmed through factor analysis. Reliability analyses among the factors revealed strong $\alpha$ values of $.89, .91$, and .92 for Interaction, Disconnection, and Disruption, respectively. Concurrent validity was evidenced through comparisons of the PIPPS with indicators of social competence from peer sociometric ratings and direct play observation and through comparisons between PIPPS data and the Social Skills Rating System (Gresham \& Elliot, 1990). Further evidence for the validity of the PIPPS when compared to preschool classroom behaviors has been documented by Coolahan et al. (2000).

\section{Procedure}

This researchwas approved by the University's Institutional ReviewBoard andwas conducted in a manner consistent with its guidelines for research. Participants were recruited using two methods. Preschool centers were identified through the child care directory search provided by the North Carolina Division of Child Development (http://ncchildcare.dhhs.state.nc.us/general/home.asp) or through relationships existing between one of the researchers and childcare directors in Tennessee. Nineteen of 20 center directors contacted by phone agreed to consider participation and received packets via mail that included an informational letter, an Informed Consent Form, and a Center Agreement Form. After agreeing to participate, directors received informed consent forms via mail to be distributed to parents and teachers of children between the ages of 3 and 5; teachers sent forms home with their students. Informed consent forms were returned to the researchers in self-addressed, stamped envelopes. Consenting parents and teachers received via mail packets containing the measures described and other rating scales that were part of a larger study. Scales were counterbalanced, and raters were instructed to complete them in the order received. Completed packets were returned by teachers and parents in self-addressed, stamped envelopes. Reminder notes were distributed periodically to early childhood centers in an effort to increase the response rate. Of the 179 parents and teachers who provided informed consent, $117(65 \%)$ returned questionnaire packets. For the 44 children participating in the current study, one school contributed 17 sets of data $(38.6 \%)$, two contributed 5 sets each (11.4\% each), and the other 8 schools contributed 4 or fewer sets (38.6\%). Parents were compensated with $\$ 15$ for each child, and teachers received $\$ 10$ per student they rated.

\section{RESULTS}

Means, $S D$ values, and internal consistency reliabilities for the study scales (see Table 2) are consistent with those reported previously (Carey \& McDevitt, 2000; Fantuzzo et al., 1998; Pianta, 2001). Independent samples $t$ tests comparing boys and girls were performed on all study scales; two displayed statistically significant differences. Teachers reported more conflict in their relationships with boys $(M=23.00, S D=10.67)$ than with girls $[M=17.20, S D=6.98, t(29.26)=$ 
$-2.06, p=.049]$. Boys $(M=26.26, S D=6.49)$ also exhibited significantly greater play disruption than girls $[M=20.32, S D=4.20, t(29.08)=-3.48, p=.002]$.

Table 2

Descriptive Statistics and Correlations among Study Variables

\begin{tabular}{lccccccc}
\hline & 1 & 2 & 3 & 4 & 5 & $M$ & $S D$ \\
\hline Easy/Difficult temperament & .89 & & & & & 16.29 & 2.28 \\
S-T conflict & .10 & .90 & & & & 19.70 & 9.13 \\
S-T dependency & .25 & $.52^{\mathrm{a}}$ & .65 & & & 9.95 & 4.00 \\
S-T closeness & .01 & -.11 & .23 & .87 & & 45.80 & 6.12 \\
Play disruption & .16 & $.75^{\mathrm{a}}$ & $.35^{\mathrm{b}}$ & .05 & .87 & 22.89 & 6.03 \\
\hline
\end{tabular}

Note: $N=44$. Values on the main diagonal represent Cronbach's alpha. S-T $=$ StudentTeacher.

${ }^{\mathrm{a}} p<.001 ;{ }^{\mathrm{b}} p<.05$.

Moderated multiple regression analyses, based on Aiken and West (1991), were employed to examine the predictors of Play Disruption (see Table 3). Three separate hierarchical regressions were conducted. Gender was entered in Step 1 to control for the differences observed between girls and boys. In Step 2, the Easy/Difficult temperament variable and one measure of student-teacher relationship quality (Conflict, Closeness, or Dependency) were entered (e.g., Conflict, in the first regression analysis). The variables entered in Step 2were centered. In Step 3, the corresponding Temperament $\times$ Student-Teacher Relationship Quality interaction term was entered (e.g., Temperament $\times$ Conflict, in the first regression analysis). 
Table 3

SequentialRegressions: Play Disruption Regressed on Gender, Easy/Difficult Temperament, Student-Teacher Relationship Quality, and the Temperament $\times$ Student-Teacher Relationship Quality Interaction

\begin{tabular}{cccc}
\hline & S-T conflict & S-T closeness & S-T dependency \\
\hline Step 1: Gender (B) & $5.94^{\mathrm{a}}$ & $5.94^{\mathrm{a}}$ & $5.94^{\mathrm{a}}$ \\
Constant & 14.38 & 14.38 & 14.38 \\
$R^{2}$ change & $.24^{\mathrm{a}}$ & $.24^{\mathrm{a}}$ & $.24^{\mathrm{a}}$ \\
Step 2: Gender (B) & $3.52^{\mathrm{a}}$ & $6.05^{\mathrm{a}}$ & $5.68^{\mathrm{a}}$ \\
Temperament (B) & .28 & .47 & .29 \\
S-T relationship (B) & $.42^{\mathrm{b}}$ & .07 & $.42^{\mathrm{c}}$ \\
Constant & 17.62 & 14.19 & 14.83 \\
$R^{2}$ change & $.40^{\mathrm{b}}$ & $.04^{\mathrm{a}}$ & $.10^{\mathrm{d}}$ \\
Step 3: Gender (B) & $3.18^{\mathrm{a}}$ & $5.99^{\mathrm{a}}$ & $5.52^{\mathrm{a}}$ \\
Temperament (B) & .24 & .44 & .34 \\
S-T relationship (B) & $.38^{\mathrm{b}}$ & .08 & $.38^{\mathrm{d}}$ \\
Temp $\times$ STRS (B) & $.06^{\mathrm{c}}$ & -.02 & .09 \\
Constant & 18.03 & 14.29 & 14.85 \\
$R^{2}$ change & $.05^{\mathrm{c}}$ & .00 & .02 \\
Full Model $R^{2}$ & .69 & .28 & .37 \\
Full Model $F, p$ & $21.81, p<.001$ & $3.84, p=.010$ & $5.68, p=.001$ \\
\hline
\end{tabular}

Note. For Full Model, $d f=4,39$. S-T $=$ Student-Teacher.

${ }^{\mathrm{a}} p<.01 ;{ }^{\mathrm{b}} p<.001 ;{ }^{\mathrm{c}} p<.05 ;{ }^{\mathrm{d}} p<.10$.

In the first sequential multiple regression analysis, Play Disruption was regressed on gender, Easy/Difficult Temperament, Student-Teacher Conflict, and the Temperament $\times$ Conflict interaction (see Table 3, first column). Statistically significant changes in $R 2$ resulted in each step. Specifically, after gender was controlled, Student-Teacher Conflict and the Temperament $\times$ Conflict interaction (but not Temperament) predicted a child's level of Play Disruption. Because of the statistically significant Temperament $\times$ Conflict interaction, the relationship between Easy/Difficult Temperament and Play Disruption was plotted in Figure 1 for three different levels of Student-Teacher Conflict (as suggested by Cohen \& Cohen, 1983): $1 S D$ below the mean (low Conflict, $z=-2.28$ ), the mean (mean Conflict, $z=0$ ), and $1 S D$ above the mean (high Conflict, $z=2.28$ ). Post hoc probing indicated that the slope of the high Student-Teacher Conflict regression line was statistically significant $[t(40)=2.46, p=.009]$. The slopes of neither the mean Conflict regression line $[t(40)=0.84, p=.203]$ nor the low Conflict regression line $[t(40)=-1.22, p=.115]$ were statistically significant. Thus, Student-Teacher Conflict moderated the relationship between Temperament and Play Disruption. Specifically, the association was attenuated for low conflict student-teacher relationships. 


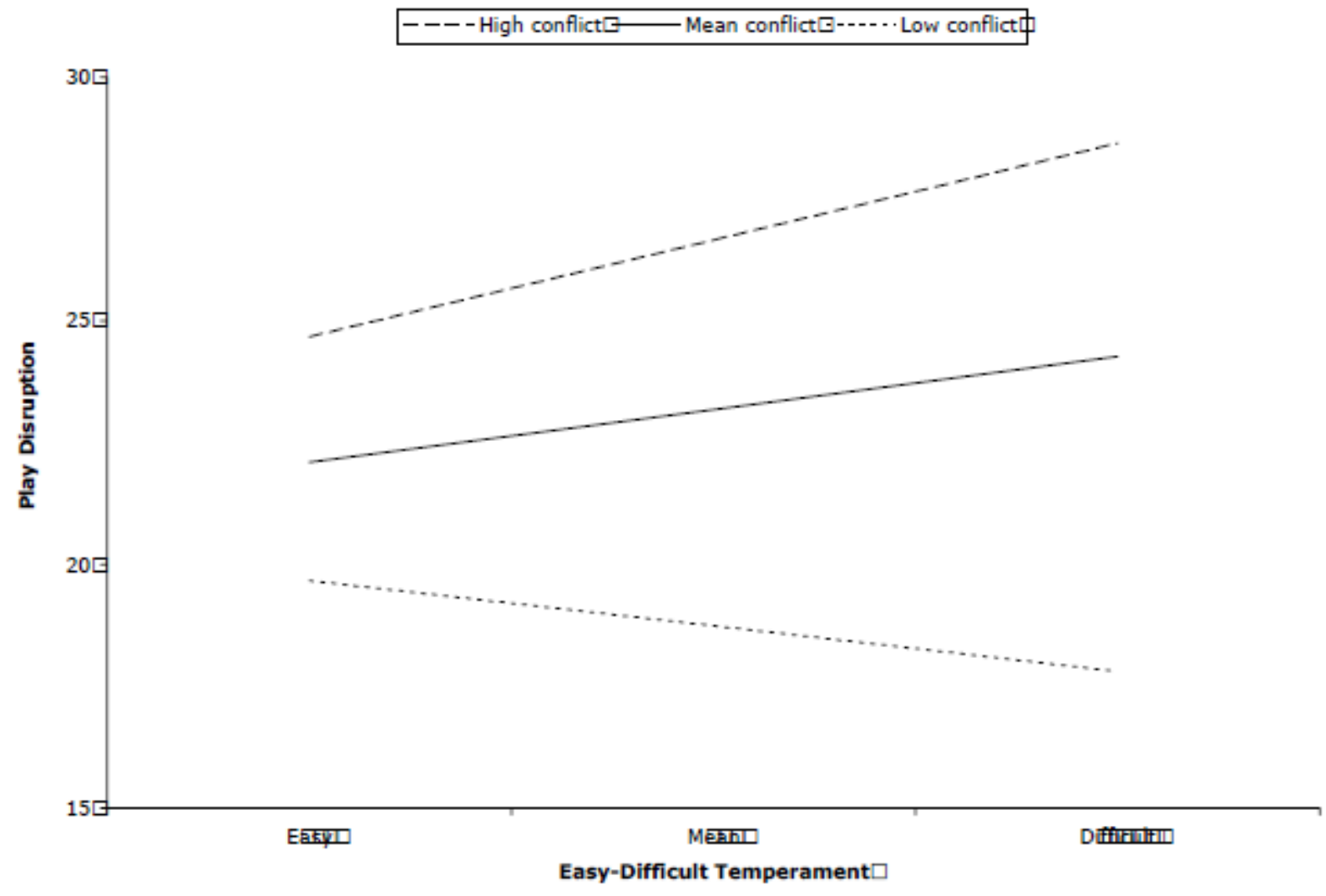

FIGURE 1. Regression of play disruption on Easy/Difficult temperament at three values of student-teacher conflict (centered data).

In the second sequential multiple regression analysis, Play Disruption was regressed on gender, Easy/Difficult Temperament, Student-Teacher Closeness, and the Temperament $\times$ Closeness interaction (see Table 3, second column). Statistically significant changes in $R 2$ resulted in Steps 1 and 2, but not in Step 3. Although the change in $R 2$ was statistically significant in Step 2, neither of the regression weights for Temperament and Closeness was. Thus, after gender was controlled, neither Student-Teacher Closeness nor Easy/Difficult Temperament predicted the level of Play Disruption.

In the third sequential multiple regression analysis, Play Disruption was regressed on gender, Easy/Difficult Temperament, Student-Teacher Dependency, and the Temperament $\times$ Dependency interaction (see Table 3, third column). Statistically significant changes in $R 2$ resulted in only Step 1. Step 2 resulted in a change in $R 2$ that did not reach the conventional level of statistical significance (i.e., $p=.053$ ), but that was consistent with study hypotheses. Step 3 did not result in a statistically significant change in $R 2$. Thus, after gender was controlled, Student-Teacher Dependency predicted the level of Play Disruption. Specifically, more dependent relationships predicted more disruptive play. 


\section{DISCUSSION}

Results of this study support previous findings that there are associations between studentteacher relationship quality and socially competent behaviors (Howes, Hamilton, \& Matheson, 1994; Howes, Matheson, et al., 1994; Pianta \& Stuhlman, 2004). Simply put, student-teacher relationships matter, particularly for preschool children who display difficult temperament patterns. More specifically, less conflictual student-teacher relationships are associated with less disruptive peer play. Although the results do not support a link between child temperament and play disruption, perhaps the most important finding is the interaction between temperament and student-teacher conflict in the prediction of disruptive peer play. This interaction supports the use of the goodness-offit model in the context of ecological assessments (Gaddis \& Hatfield, 1997).

We did not observe strong correlations between a child's temperament and level of disruptive peer play $(r=.16)$, but our research indicates that the situation is more complex than mere bivariate correlations. Our data show that, for young children, more difficult temperaments are associated with more disruptive peer play when the student-teacher relationship is characterized by high conflict.This result is as expected based on the literature (where difficult temperament generally is associated with undesirable outcomes). However, in student-teacher relationships with low or even typical levels of conflict, there is no association between easy/difficult temperament and disruptive peer play. Again, student-teacher relationships matter: Lower levels of conflict in student-teacher relationships may reduce the risk of negative behavioral outcomes generally associated with preschoolers who have difficult temperaments.

We believe that this particular finding is especially important given the body of research supporting links between temperament and social and behavioral outcomes. The literature indicates that children with more difficult temperaments are more likely to experience negative social and behavioral outcomes. Thus, teachers and school psychologists might expect children who display difficult behavioral styles to interact poorly with their peers. However, our data encourage the consideration of mitigating factors, such as student-teacher relationship quality. The likelihood that a child with a difficult behavioral style will exhibit disruptive behaviors during peer play interactions may be reduced if there is little or no conflict in the student-teacher relationship. For school psychology practitioners, this is exciting news, for we now have a potential target for intervention. An ecological approach requires that school psychologists expand the focus of assessments beyond a traditional "child as problem" conceptualization to include consideration of elements of the environment that may interact with within-child traits to predict outcomes. Environmental variables are more amenable to change than are within-child traits and thereby can serve as intervention targets. The current findings suggest that student-teacher relationship quality functions as a protective factor that moderates the link between difficult child temperament and problems with social interactions. Even for children who display difficult temperament patterns, a relationship with a teacher characterized by a low or even typical degree of conflict may decrease the likelihood of negative social outcomes, at least in terms of peer play.

The present findings are consistent with previous research identifying the benefits of positive student-teacher relationships for children at risk for social, behavioral, and/or academic difficulties (Burchinal et al., 2002; Hughes et al., 1999). Hamre and Pianta (2006) suggested that positive interactions with teachers might allow for the development of adaptive behaviors that can improve behavioral and social outcomes for some children. Indeed, particularly during early childhood, it is through interpersonal interactions that young children develop social and interpersonal skills. During these interactions, children have opportunities to practice their social skills and to be reinforced for appropriate behaviors. 


\section{Limitations and Future Directions}

The current research has several limitations. Although the overall sample from which participants were drawn was sufficient $(N=117)$, the current sample $(N=44)$ was smaller due to difficulty in obtaining matched parent-teacher data. A larger sample would have increased the statistical power and would have allowed the use of more complex analyses. Hierarchical multiple regression is recommended for examining moderator variables (Aiken \&West, 1991), but researchers have noted the difficulties in obtaining statistically significant interactions (Plomin \& Daniels, 1984) and moderated effects in field research (McClelland \& Judd, 1993). Future research should employ larger samples to allow the use of statistical techniques that may elucidate more fully these complex relationships.

The generalizability of our findings may be limited by the composition of the sample. Although the preschool centers participating in this study represented urban and rural areas, the sample was relatively homogeneous in terms of ethnicity, parent education, and geographic location. Specifically, the children were predominately White, of college-educated parents, and living in the Southeast. Future research should include more diverse samples to enhance the generalizability of the findings.

Controlling for gender rather than examining it explicitly represents another limitation. The sample size did not allow us to test gender differences in these moderated relationships, and the literature provides little guidance regarding the nature of possible gender effects in these relationships. Consistent with earlier research, teachers in this study reported more conflict in their relationships with boys than with girls and rated boys as having more conflictual play behaviors than girls. Future research should explore the nature of gender effects among these variables to enhance current literature and theory.

The manner in which ratings were obtained also may have influenced the results. Parents provided ratings of their children's temperaments, whereas teachers provided ratings of both peer play behaviors and student-teacher relationship quality. Comparing teacher ratings to parent ratings may have increased the correlation between the former two variables (due to common method variance) while attenuating the relationship between the former variables and the latter (due to the general lack of convergence between parent and teacher reports of behavior; Achenbach, McConaughy, \& Howell, 1987). Future research should assess and control these issues by including teacher-rated temperament, parent-rated peer play behavior, and third-party observations of all study variables.

A final concern may be that student-teacher relationship quality and a child's social competence do not represent independent dimensions; a child's social competence likely includes good relationships with others. Although there may be conceptual overlap, an item-level examination of the instruments used to measure student-teacher relationship quality and peer play indicated no overlap in content. Thus it is not a concern in the current study. Nonetheless, future researchers should be aware of the issue, particularly when studying the broader construct of social competence as an outcome (rather than the narrower peer play examined here).

\section{Implications}

Ultimately, these findings illustrate the importance of considering the potential impact of student-teacher relationship quality on young children's social behaviors. Teachers can provide children play opportunities and guide their play interactions (Creasey, Jarvis, \& Berk, 1998). Given the significance of social interactions to early development, teachers have an opportunity to support children as they navigate play experiences. Teacher intervention can be particularly important for children who already may be at risk for problems with social development. 
For school psychologists, these findings also speak to the importance of evaluating studentteacher relationship quality when attempting to understand the nature of preschool children's difficulties. Focusing on relationship quality expands the scope of school-based assessments from the traditional practice of diagnosing disabilities to a more positive approach that considers variables external to the child that may serve as intervention targets. Because the evaluation of teacher variables typically is not done in the context of early childhood assessments, school psychologists may be reluctant to pursue the evaluation of relationship quality. By the same token, teachers might perceive attempts to assess relationship quality as implying that they are to blame for a child's difficulties. Therefore, school psychologists should be sensitive and acknowledge a teacher's discomfort if it arises. Fundamentally, the practice of assessing student-teacher relationship quality is consistent with an ecological approach and is advocated as best practice for school psychologists involved in early childhood assessments (Sheridan \& Gutkin, 2000).

The current findings should be utilized to guide the development of interventions aimed at improving student-teacher relationships, particularly as these relationships are one of the most powerful processes through which teachers can promote healthy social-emotional development (Deiro, 2005), adjustment to (Birch \& Ladd, 1997; Ladd et al., 1999), and success in school (Hamre \& Pianta, 2006). Mashburn and Pianta (2006) acknowledge the usefulness of interventions aimed at improving the quality of children's interactions and relationships with their early teachers, thereby facilitating other classroom interactions and academic successes. Ultimately, these findings suggest that preschool teachers have the opportunity to utilize the relationships they build with students to facilitate the development of social competency. 


\section{REFERENCES}

Achenbach, T. M., McConaughy, S. H., \& Howell, C. T. (1987). Child/adolescent behavioral and emotional problems: Implications of cross-informant correlations for situational specificity. Psychological Bulletin, 101, $213-232$.

Aiken, L. S., \& West, S. G. (1991). Multiple regression: Testing and interpreting interactions. Newbury Park, CA: Sage.

Birch, S. H., \& Ladd, G. W. (1997). The teacher-child relationship and children's early school adjustment. Journal of School Psychology, 35, $61-79$.

Birch, S. H., \& Ladd, G. W. (1998). Children's interpersonal behaviors and the teacher-child relationship. Developmental Psychology, 34, $934-946$.

Blair, K. A., Denham, S. A., Kochanoff, A., \& Whipple, B. (2004). Playing it cool: Temperament, emotion regulation, and social behavior in preschoolers. Journal of School Psychology, 42, 419 - 443.

Bohlin, G., Hagekull, B., \& Andersson, K. (2005). Behavioral inhibition as a precursor of peer social competence in early school age: The interplay with attachment and nonparental care. Merrill-Palmer Quarterly, 51, 1- 19.

Burchinal, M. R., Peisner-Feinberg, E., Pianta, R., \& Howes, C. (2002). Development of academic skill from preschool through second grade: Family and classroom predictors of developmental trajectories. Journal of School Psychology, 40, 415 - 436.

Carey, W. B. (1998). Temperament and behavior problems in the classroom. School Psychology Review, $27,522-533$.

Carey,W. B.,\& McDevitt, S. C. (2000). The Carey Temperament Scales testmanual. Scottsdale, AZ:Behavioral-Development Initiatives.

Cohen, J., \& Cohen, P. (1983). Applied multiple regression/correlation for the behavioral sciences (2nd ed.). Hillsdale, NJ: Lawrence Erlbaum.

Coolahan, K., Fantuzzo, J., Mendez, J., \& McDermott, P. (2000). Preschool peer interactions and readiness to learn: Relationships between classroom peer play and learning behaviors and conduct. Journal of Educational Psychology, 92,458 - 465.

Coplan, R. J., Barber, A. M., \& Lagace-Seguin, D. G. (1999). The role of child temperament as a predictor of early literacy and numeracy skills in preschoolers. Early Childhood Research Quarterly, 14, $537-553$.

Corapci, F. (2008). The role of child temperament on Head Start preschoolers' social competence in the context of cumulative risk. Journal of Applied Developmental Psychology, 29, 1 - 16.

Creasey, G. L., Jarvis, P. A., \& Berk, L. E. (1998). Play and social competence. In O. N. Saracho \& B. Spodek (Eds.), Multiple perspectives on play in early childhood education (pp. 116 - 143). Albany, NY: State University of New York Press.

Davis, H. A. (2003). Conceptualizing the role and influence of student-teacher relationships on children's social and cognitive development. Educational Psychologist, 38, 207 - 234. 
Deiro, J. A. (2005). Teachers do make a difference: The teacher's guide to connecting with students. Thousand Oaks, CA: Corwin Press, Inc.

Denham, S. A. (2006). Social-emotional competence as support for school readiness: What is it and how do we assess it? Early Education and Development, 17, 57 - 89.

DiLalla, L. F. (1998). Daycare, child, and family influences on preschoolers' social behaviors in a peer play setting. Child Study Journal, 28, 223 - 245.

DiLalla, L. F., Marcus, J. L., \& Wright-Phillips, M. V. (2004). Longitudinal effects of preschool behavioral styles on early adolescent school performance. Journal of School Psychology, 42, 385 - 401.

Else-Quest, N. M., Hyde, J. S., Goldsmith, H. H., \& Van Hulle, C. A. (2006). Gender differences in temperament: A meta-analysis. Psychological Bulletin, 132, 33 - 72.

Fantuzzo, J., Coolahan, K., Mendez, J., McDermott, P., \& Sutton-Smith, B. (1998). Contextually-relevant validation of peer play constructs with African-American Head Start children: Penn Interactive Peer Play Scale. Early Childhood Research Quarterly, 13, 411 - 431.

Fantuzzo, J., Sekino, Y., \& Cohen, H. L. (2004). An examination of the contributions of interactive peer play to salient classroom competencies for urban Head Start children. Psychology in the Schools, 41, 323 $-336$.

Fantuzzo, J.W., Bulotsky-Shearer, R., Fusco, R. A., \& McWayne, C. (2005). An investigation of preschool classroom behavioral adjustment problems and social - emotional school readiness competencies. Early Childhood Research Quarterly, 20, 259-275.

Gaddis, L. R., \& Hatfield, L. (1997). Characteristics of the learning environment: Students, teachers, and their interactions. In J. L. Swartz \&W. E. Martin (Eds.), Applied ecological psychology for schools within communities: Assessment and intervention (pp. 31 - 54). Mahwah, NJ: Lawrence Erlbaum Associates Publishers.

Gresham, F. M., \& Elliott, S. M. (1990). The social skills rating system. Circle Pines, MN: American Guidance Service. Hamre, B. K., \& Pianta, R. C. (2001). Early teacher-child relationships and the trajectory of children's school outcomes through eighth grade. Child Development, 72, 625 - 638 .

Hamre, B. K.,\&Pianta, R. C. (2006). Student-teacher relationships. In G. G. Bear \& K.M. Minke (Eds.), Children's needs III: Development, prevention, and intervention (pp. 59 - 72). Bethesda, MD: National Association of School Psychologists.

Howes, C. (2000). Social-emotional classroom climate in child care, child-teacher relationships, and children's second grade peer relations. Social Development, 9, $191-204$.

Howes, C., \& Hamilton, C. E. (1993). The changing experience of child care: Changes in teachers and in teacher-child relationships and children's social competence with peers. Early Childhood Research Quarterly, 8, $15-32$.

Howes, C., Hamilton, C. E., \& Matheson, C. C. (1994). Children's relationships with peers: Differential associations with aspects of the teacher-child relationship. Child Development, 65, 253-263. 
Howes, C., Matheson, C. C., \& Hamilton, C. E. (1994). Maternal, teacher, and child care history correlates of children's relationships with peers. Child Development, 65, $264-273$.

Hughes, J. N., Cavell, T. A., \& Jackson, T. (1999). Influence of the teacher-student relationship on childhood conduct problems: A prospective study. Journal of Clinical Child Psychology, 28, 173 - 184.

Hughes, J. N., Cavell, T. A., \& Willson, V. (2001). Further support for the developmental significance of the student-teacher relationship. Journal of School Psychology, 39, 289- 301.

Johnson, C., Ironsmith, M., Snow, C. W., \& Poteat, G. M. (2000). Peer acceptance and social adjustment in preschool and kindergarten. Early Childhood Education Journal, 27, 207 - 212.

Keogh, B. K. (1989). Applying temperament research to school. In G. A. Kohnstamm, J. E. Bates, \& M. K. Rothbart (Eds.), Temperament in childhood (pp. 437 -450). New York: John Wiley \& Sons.

Keogh, B. K. (1994). Temperament and teachers' views of teachability. In W. B. Carey \& S. C. McDevitt (Eds.), Prevention and early intervention: Individual differences as risk factors for the mental health of children: A festschrift for Stella Chess and Alexander Thomas (pp. 246 - 254). Philadelphia, PA:

Brunner/Mazel, Inc.

Keogh, B. K. (2003). Temperament in the classroom: Understanding individual differences. Baltimore: Paul H. Brookes Publishing.

La Paro, K. M., \& Pianta, R. C. (2000). Predicting children's competence in the early school years: A meta-analytic review. Review of Educational Research, 70, 443 - 484.

Ladd, G. W., Birch, S. H., \& Buhs, E. S. (1999). Children's social and scholastic lives in kindergarten: Related spheres of influence? Child Development, 70, $1373-1400$.

Ladd, G. W., \& Burgess, K. B. (2001). Do relational risks and protective factors moderate the linkages between childhood aggression and early psychological and school adjustment? Child Development, 72, $1579-1601$.

Ladd, G. W., Herald, S. L., \& Kochel, K. P. (2006). School readiness: Are there social prerequisites? Early Education and Development, 17, 115 - 150.

Ladd, G.W., Kochenderfer, B. J., \& Coleman, C. C. (1996). Friendship quality as a predictor of young children's early school adjustment. Child Development, 67, $1103-1118$.

Ladd, G.W., \& Price, J. M. (1987). Predicting children's social and school adjustment following the transition from preschool to kindergarten. Child Development, 58, 1168 - 1189.

LaForce, C. B, \& Oxford, M. L. (2008). Trajectories of social withdrawal from grades 1 to 6: Prediction from early parenting, attachment, and temperament. Developmental Psychology, 44, 1298 - 1313.

Martin, R. P. (1989). Activity level, distractibility, and persistence: Critical characteristics in early schooling. In G. A. Kohnstamm, J. E. Bates, \& M. K. Rothbart (Eds.), Temperament in childhood (pp. 451 - 461). New York: John Wiley \& Sons.

Mashburn, A. J., \& Pianta, R. C. (2006). Social relationships and school readiness. Early Education and Development, 17, $151-176$. 
McClelland, G. H.,\& Judd, C. M. (1993). Statistical difficulties of detecting interactions andmoderator effects. Psychological Bulletin, 114, $376-390$.

McDevitt, S. C., \& Carey, W. B. (1978). The measurement of temperament in 3- to 7-year old children. Journal of Child Psychology and Psychiatry, 19, 245 - 254.

Mendez, J. L., Fantuzzo, J., \& Cicchetti, D. (2002). Profiles of social competence among low-income African-American preschool children. Child Development, 73, 1085 - 1100.

Mendez, J. L., McDermott, P., \& Fantuzzo, J. (2002). Identifying and promoting social competence with African American preschool children: Developmental and contextual considerations. Psychology in the Schools, 39, $111-123$.

Murray, C., \& Murray, K. M. (2004). Child level correlates of student-teacher relationships: An examination of demographic characteristics, academic orientations, and behavioral orientations. Psychology in the Schools, 41, $751-762$.

Neisworth, J. T., \& Bagnato, S. J. (2005). DEC recommended practices: Assessment. In S. Sandall, M. L. Hemmeter, B. J. Smith, \& M. E. McLean (Eds.), DEC recommended practice: A comprehensive guide for practical application in early intervention/early childhood special education (pp. 45 - 70). Longmont, CO: Sopris West.

Novosad, C., \& Thoman, E. B. (1999). Stability of temperament over the childhood years. American Journal of Orthopsychiatry, 69, $457-464$.

Pianta, R. C. (1999). Enhancing relationships between children and teachers. Washington, DC: American Psychological Association.

Pianta, R. C. (2001). Student-teacher relationship scale: Professional manual. Odessa, FL: Psychological Assessment Resources.

Pianta. R. C., \& Nimetz, S. L. (1991). Relationships between teachers and children: Associations with behavior at home and in the classroom. Journal of Applied Developmental Psychology, 12, $379-393$.

Pianta, R. C., Nimetz, S. L., \& Bennett, E. (1997). Mother-child relationships, teacher-child relationships, and school outcomes in preschool and kindergarten. Early Childhood Research Quarterly, 12, 263 - 280.

Pianta, R. C., Steinberg, M. S., \& Rollins, K. B. (1995). The first two years of school: Teacher-child relationships and deflections in children's classroom adjustment. Development and Psychopathology, 7 , $295-312$.

Pianta, R. C., \& Stuhlman, M. W. (2004). Teacher-child relationships and children's success in the first years of school. School Psychology Review, 33, $444-458$.

Plomin, R., \& Daniels, D. (1984). The interaction between temperament and environment: Methodological considerations. Merrill-Palmer Quarterly, 30, 149 - 162.

Raver, C. C., \& Knitzer, J. (2002). Ready to enter: What research tells policymakers about strategies to promote social and emotional school readiness among three- and four-year-old children. New York: National Center for Children in Poverty. 
Rose-Krasnor, L. (1997). The nature of social competence: A theoretical review. Social Development, 6, $111-135$.

Rothbart,M. L.,\& Bates, J. E. (2006). Temperament. InN. Eisenberg (Vol. Ed.),W. Damon, \& R.M. Lerner (Eds.), Handbook of child psychology: Vol. 3. Social, emotional, and personality development (6th ed., pp. 99 - 166). Hoboken, NJ: John Wiley \& Sons, Inc.

Sarafino, E. P. (2000). Tests of the relationship between children's temperament and asthma and of the reliability and validity of the Brief Scale of Temperament. Journal of Genetic Psychology, 161, 23 - 36.

Sheridan, S. M., \& Gutkin, T. B. (2000). The ecology of school psychology: Examining and changing our paradigm for the 21st century. School Psychology Review, 29, 485 - 502.

Sroufe, L. A., Egeland, B., Carlson, E. A., \& Collins, W. A. (2005). The development of the person: The Minnesota study of risk and adaptation from birth to adulthood. New York: Guilford Press.

Thomas, A., \& Chess, S. (1977). Temperament and development. New York: Brunner/Mazel.

Thomas, A.,\& Chess, S. (1982). Temperament and follow-up to adulthood. In R. Porter \& G.M. Collins (Eds.), Temperamental differences in infants and young children (pp. 168 - 175). London: Pitman Books.

Thomas, A., Chess, S., \& Birch, H. G. (1968). Temperament and behavior disorders in children. New York: New York University Press.

Walker, S., Berthelsen, D., \& Irving, K. (2001). Temperament and peer acceptance in early childhood: Sex and social status differences. Child Study Journal, 31, 177 - 192. 